\title{
Osteoclast Response to Bioactive Surface Modification of Hydroxyapatite
}

\author{
Yohei Okazaki1, Yasuhiko Abe1*, Keisuke Yasuda1, Kyou Hiasa1, Isao Hirata² \\ ${ }^{1}$ Department of Advanced Prosthodontics, Applied Life Sciences, Institute of Biomedical \& Health Sciences, \\ Hiroshima University, Hiroshima, Japan \\ ${ }^{2}$ Department of Biomaterial Science, Basic Life Sciences, Institute of Biomedical \& Health Sciences, \\ Hiroshima University, Hiroshima, Japan \\ Email: ${ }^{*}$ abey@hiroshima-u.ac.jp
}

Received 20 May 2014; revised 27 June 2014; accepted 16 July 2014

Copyright (C) 2014 by authors and Scientific Research Publishing Inc.

This work is licensed under the Creative Commons Attribution International License (CC BY).

http://creativecommons.org/licenses/by/4.0/

cC) (i) Open Access

\section{Abstract}

The aim of this study was to evaluate the in vitro response of osteoclast-like cells (RAW 264.7 cells) to a bioactive hydroxyapatite (HAP) surface that was modified using the $30 \%$ phosphoric acid-etching procedure reported in our previous paper (2013). The cells on the bioactive HAP surface were multinucleated and were larger than those on the untreated HAP surface. The cell occupancies were greater on the bioactive HAP surface than on the untreated HAP surface at 7, 14, 21, and 28 days of differentiation; in particular, the values at 21 and 28 days were significantly larger $(P<0.05$ and $P<0.01$, respectively). These findings show that the bioactive HAP surface may enhance the adhesion and differentiation of RAW 264.7 cells as well as osteoblast-like cells, indicating its potential as a superior surface for bone tissue engineering.

\section{Keywords}

Hydroxyapatite, Phosphoric Acid, Ca/P Ratio, Osteoclast

\section{Introduction}

Hydroxyapatite $\left[\mathrm{Ca}_{10}\left(\mathrm{PO}_{4}\right)_{6}(\mathrm{OH})_{2}\right]$ (HAP) shows great potential as a scaffolding material for bone tissue engineering because of its bioactive and osteoconductive properties in vivo [1]. HAP is bioactive but is not as bioresorbable as $\beta$-tricalcium phosphate $\left[\beta-\mathrm{Ca}_{3}\left(\mathrm{PO}_{4}\right)_{2}\right](\beta-\mathrm{TCP})$, and is most thermodynamically stable at a physiological $\mathrm{pH}$ (7.4) [2]. This material supports the adhesion, proliferation, and differentiation of osteogenesis-related cells such as osteoblasts, osteoclasts and mesenchymal stem cells. Therefore, scaffolds fabricated from HAP that

"Corresponding author. 
exhibit high porosity and pore interconnectivity are commonly used in clinical practice [1]-[4].

According to Dorozhkin [5] [6], HAP dissolution occurs through five steps, which results in changes of the surface composition to $\mathrm{Ca}_{3}\left(\mathrm{PO}_{4}\right)_{2}$ (TCP) and $\mathrm{CaHPO}_{4}$ (dicalcium phosphate dehydrate, DCPD). Bertazzo et al. [7] proposed three initial phases that occur before equilibrium is established between the HAP surface and biological fluids. DCPD is formed on the modified surface once this equilibrium is reached, which is followed by processes that promote the integration of the HAP surface with the tissue, such as protein adsorption and cell adhesion. However, a bioactive surface with a $\mathrm{Ca} / \mathrm{P}$ ratio of less than 1 has high solubility and acidity, and is therefore not suitable for implantation in the body [2]. One way to resolve this issue is to modify the supersurface layer of $\mathrm{HAP}(\mathrm{Ca} / \mathrm{P}$ ratio $=1.67)$ to mimic that of $\beta-\mathrm{TCP}(\mathrm{Ca} / \mathrm{P}$ ratio $=1.50)$ [8] [9].

One potential approach for acquiring the desired surface of HAP is the sintering method; however, this method is complex and unstable [2]. Therefore, we hypothesized that an acid-etching procedure with phosphoric acid could be used to alter the $\mathrm{Ca} / \mathrm{P}$ ratio of the HAP surface directly in order to achieve a bioactive surface that best mimics the initial phases proposed by Bertazzo et al. [7]. In our previous study, we found that the $\mathrm{Ca} / \mathrm{P}$ ratio of a nanostructured HAP surface could be effectively altered using a 30\% phosphoric acid-etching process, which was further found to enhance the initial adhesion, proliferation, and differentiation of MC3T3-E1 cells [10].

Osteoclasts are multinucleated cells derived from hematopoietic stem cells and play a key role in bone resorption [11]. When initiating bone resorption, osteoclasts become polarized, and three distinct membrane domains appear: a ruffled border, a sealing zone, and a functional secretory domain [12]. On the other hand, bone marrow stromal cells and osteoblasts produce membrane-bound and soluble receptor activator of NF-kB ligand (RANKL)/tumor necrosis factor (TNF)-related activation-induced cytokine (TRANCE)/osteoprotegerinligand (OPGL)/osteoclast differentiation factor (ODF), an important positive regulator of osteoclast formation [13]. During bone remodeling, osteoclast-induced resorption precedes osteoblast-induced bone formation [14]. Thus, an ideal bioactive HAP surface should be capable of activating not only osteoblasts but also osteoclasts [15].

Therefore, the aim of this study was to evaluate the in vitro response of osteoclast-like cells to the bioactive HAP surface modified by the $30 \%$ phosphoric acid-etching procedure [10].

\section{Materials and Methods}

\subsection{Sample Preparation}

HAP plates (thickness, 2 mm; width, $10 \mathrm{~mm}$; length, $10 \mathrm{~mm}$ ) (APP-101; Pentax; Tokyo, Japan) were used in this study. The HAP plates were treated with $30 \%$ phosphoric acid $\left[\mathrm{H}_{3} \mathrm{PO}_{4}\right]$ (lot no. T1949; Sigma-Aldrich Japan; Tokyo, Japan) solution for 10 minutes at $25^{\circ} \mathrm{C}$, followed by rinsing 3 times with ultrapure water (MilliQ water: $>18 \mathrm{M} \Omega \mathrm{cm}$ ) to achieve the modified HAP surface, HAP-30\% PA [10]. The surface characteristics of HAP-30\% PA were then compared to the untreated HAP surface as a control using the methods described below.

\subsection{RAW264.7 Cell Culture}

The RAW 264.7 mouse macrophage/monocyte cell line (cat. no. EC91062702) was purchased from DS Pharma Biomedical Japan (Osaka, Japan). The cells were cultured on HAP or HAP-30\% PA plates that were sterilized by ultraviolet irradiation for 4 hours before being placed on the bottom of 24-well culture plates. Cells were plated at a density of $5.0 \times 10^{3}$ cells/well in Dulbecco's modified Eagle medium (lot no. RNBB4045; SigmaAldrich Japan) containing 10\% fetal bovine serum (FBS) (lot nos. F0926, 027K03911; Sigma-Aldrich Japan), 1\% penicillin-streptomycin (lot nos. P0781, 060M0811; Sigma-Aldrich Japan), and 2 mM glutamine (G6392-IVL; Sigma-Aldrich Japan) at $37^{\circ} \mathrm{C}$ in a humidified atmosphere of $5 \% \mathrm{CO}_{2}$. After reaching confluence, the medium was changed to Eagle's alpha-minimum essential medium (lot no. 019K2364; Sigma-Aldrich Japan) containing 10\% FBS, 1\% penicillin-streptomycin, 50 ng/mL RANKL (462-TR; R\&D Systems; Minneapolis, USA), and 50 $\mathrm{ng} / \mathrm{mL}$ macrophage colony-stimulating factor (416-ML; R\&D Systems). The medium was refreshed every three days.

\subsection{Scanning Electron Microscope (SEM) Observations}

Cells cultured on the HAP and HAP-30\% PA plates were fixed in phosphate-buffered saline containing 2.5\% 
glutaraldehyde (lot no. EPH0574; Wako Pure Chemical Industries; Osaka, Japan) and 2\% paraformaldehyde (lot no. L1M0063; NacalaiTesque; Kyoto, Japan) for 2 hours after 7 days of differentiation induction. Then, the cells were dehydrated through 15-minute immersion in a graded series (50\%, 70\%, 80\%, 90\%, and 99.9\%) of ethanol. An SEM (VE-8800; Keyence; Osaka, Japan) was used to observe the cell morphology.

\subsection{Tartrate-Resistant Acid Phosphatase (Trap) Staining and Occupancy of Raw264.7 Cells Adhered to the Samples}

The numbers of cells adhering to the samples at 7, 14, 21, and 28 days of differentiation induction were detected using TRAP staining kit (AK04F; Primary Cell; Sapporo, Japan) according to the manufacturer's protocol. After TRAP staining, the surface image of each sample was scanned using a confocal laser-scanning microscope (VK-8500; Keyence; Osaka, Japan). The occupancy of the cells in six $100 \times 100-\mu \mathrm{m}$ regions of interest (ROIs) of the surface was measured with the image processing software Image J. The average cell occupancy of six ROIs for each sample was calculated. The data were analyzed using one-way ANOVA and Tukey's post-hoc test for multiple comparisons $(P<0.05)$.

\section{Results}

\subsection{SEM}

SEM images of the cells on HAP and HAP-30\% PA surfaces at 7 days of differentiation induction are shown in Figure 1. The cells on the HAP plate were smaller than those on the HAP-30\% PA plate. The cells on the HAP plate were not clearly distinguishable from osteoclast precursor cells, although the sealing zone of the cells was detected. The cells on the HAP-30\% PA plate were multinucleated and were approximately $40 \mu \mathrm{m}$ in diameter larger than those on the HAP plate.

\subsection{RAW264.7 Cell Occupancy}

The results of the cell occupancy analysis at 7, 14, 21, and 28 days of differentiation induction are shown in Figure 2. The cell occupancy values on the HAP plate were significantly greater at 14, 21, and 28 days than that at 7 days of differentiation induction $(P<0.01)$. Similarly, cell occupancy values on the HAP-30\% PA plate were increased at 14,21 , and 28 days compared to that at 7 days $(P<0.01)$, and the values at 21 and 28 days were also significantly larger than that at 14 days $(P<0.01)$. For all observation periods, the cell occupancies were higher on the HAP-30\% PA plates than on the HAP plates; in particular, the values at 21 and 28 days were significantly larger $(P<0.05$ and $P<0.01$, respectively).

\section{Discussion}

The in vitro response (adhesion and differentiation) of osteoclast-like cells to the HAP-30\% PA surface was superior to that of the untreated HAP surface.

The primary cellular mechanisms responsible for bone formation are modeling and remodeling. Bone modeling
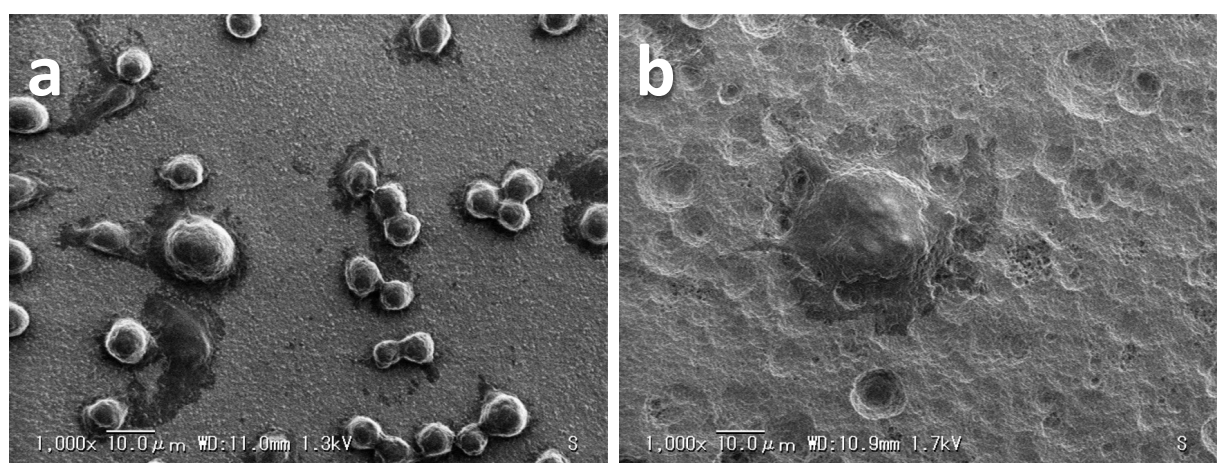

Figure 1. SEM images of the cells grown on (a) HAP and (b) HAP-30\% PA plates at 7 days of differentiation induction. Magnification, $1000 \times$; scale bar, $10.0 \mu \mathrm{m}$. 


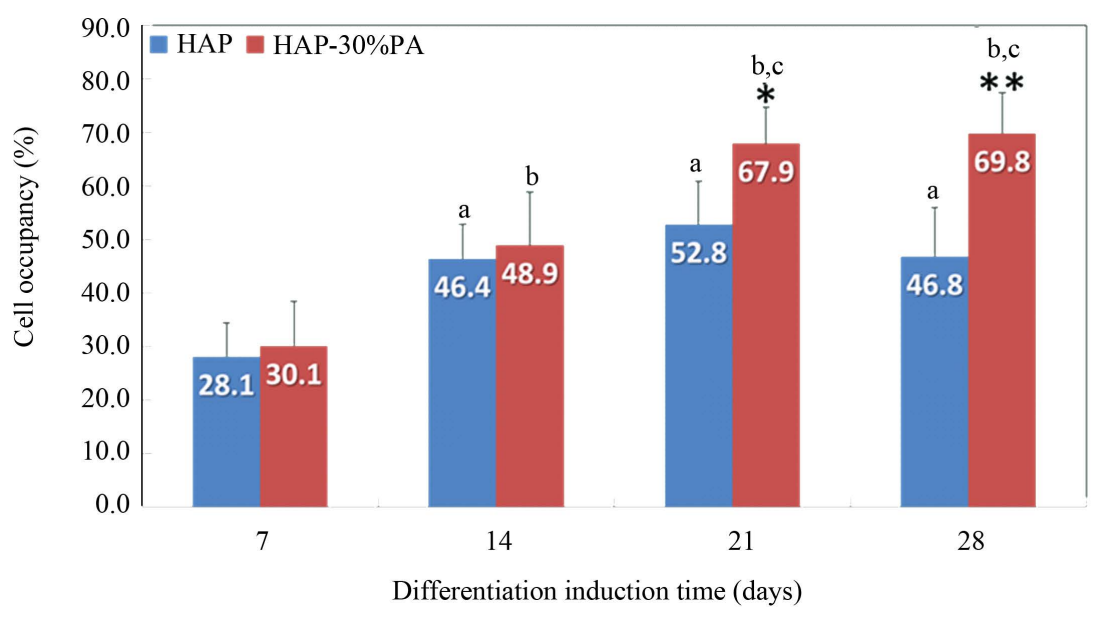

Figure 2. Cell occupancy on HAP and HAP-30\% PA plates at 7, 14, 21, and 28 days of differentiation induction. ${ }^{*} P<0.05$ at 21 days and ${ }^{* *} P<0.01$ at 28 days indicate a significant difference from HAP, respectively. ${ }^{\mathrm{a}} P<0.01$ indicates a significant difference from HAP at 7 days. ${ }^{\text {b } P}<0.01$ indicates a significant difference from HAP-30\% PA at 7 days. ${ }^{c} P<0.01$ indicates a significant difference from HAP-30\% $\mathrm{PA}$ at 14 days.

produces a change in the size and shape of bone when new bone is deposited without previous bone resorption. During bone remodeling, resorption by osteoclasts precedes bone formation by osteoblasts [14]. After migration of the osteoclasts to a resorption site, a specific membrane domain, the sealing zone, forms under the osteoclast layer. The sealing zone tightly attaches to the bone matrix and seals the resorption site, thereby protecting it from its surroundings [12]. The local regulation is bidirectional, in which osteoblasts direct the osteoclastogenesis process, whereas the products of osteoclasts and of the resorbed matrix modulate the bone formation process [14]. Thus, osteoblasts and osteoclasts form the bone multicellular unit, so that the osteoclasts regulating bone metabolism are coupled with osteoblasts in either a direct or indirect manner in vivo to promote bone resorption and consequent calcium release. In our previous study, we observed that the bioactive HAP surface (HAP-30\% PA) enhanced the initial adhesion, proliferation, and differentiation of MC3T3-E1 cells [10]; thus, we hypothesized that this surface would also show high affinity for osteoclasts.

The $\mathrm{Ca} / \mathrm{P}$ ratio of HAP is relatively high (1.67); therefore, HAP-30\% PA was designed to more closely match the theoretical value of TCP (1.50) [10] to achieve a highly soluble. In addition, this surface modification of HAP yielded a rougher and wetter surface; with increasing roughness, the contact angle of HAP-30\% PA was reduced, resulting in a super hydrophilic surface [10]. Thus, the surface might have been modified both morphometrically and chemically. The main physiological function of osteoclasts is to degrade the mineralized bone matrix. Before proteolytic enzymes can reach and degrade the collageneous bone matrix, tightly packed HAP crystals must be dissolved [12]. Therefore, a highly soluble, nanostructured bioactive HAP surface should be able to induce osteoclast adhesion. In this study, SEM images of the cells and the cell occupancies on HAP-30\% PA plates demonstrated improvement in the adhesion and differentiation of osteoclast-like cells compared to those on HAP plates. Therefore, the in vitro responses of both osteoclast-like and osteoblast-like cells appear to be superior when differentiated on HAP-30\% PA to those observed when the cells were differentiated on HAP.

\section{Conclusion}

In this study, we evaluated the in vitro response of RAW 264.7 osteoclast-like cells to a bioactive HAP surface that was modified by the $30 \%$ phosphoric acid-etching procedure (HAP- $30 \%$ PA). The cells on the HAP- $30 \%$ PA plate were multinucleated and were larger than those on the HAP plate. The cell occupancies for HAP-30\% PA at 7, 14, 21, and 28 days of differentiation induction were greater than those for HAP, with significant differences observed at 21 and 28 days $(P<0.05$ and $P<0.01$, respectively). Therefore, the bioactive HAP surface significantly promoted the adhesion and differentiation of osteoclast-like cells as well as osteoblast-like cells. In the future, the practical applications of the bioactive HAP surface will be evaluated by conducting in vivo studies. 


\section{Conflict of Interests}

There are no conflicts of interests to declare.

\section{Acknowledgements}

This study was supported in part by a Grant-in-Aid for Scientific Research (nos. 21592452 and 24592915) from the Japan Society for the Promotion of Science (JSPS) and by the Ministry of Education, Culture, Sports, Science and Technology (MEXT), Japan (2009-2011 and 2012-2014). We would also like to thank Editage ${ }^{\circledR}$ for providing editorial assistance.

\section{References}

[1] Hoppe, A., Güldal, N.S. and Boccaccini, A.R. (2011) A Review of the Biological Response to Ionic Dissolution Products from Bioactive Glasses and Glass-Ceramics. Biomaterials, 32, 2757-2774. http://dx.doi.org/10.1016/j.biomaterials.2011.01.004

[2] Dorozhkin, S.V. (2010) Bioceramics of Calcium Orthophosphates. Biomaterials, 31, 1465-1485. http://dx.doi.org/10.1016/j.biomaterials.2009.11.050

[3] Ito, Y., Tanaka, N., Fujimoto, Y., Yasunaga, Y., Ishida, O., Agung, M. and Ochi, M. (2004) Bone Formation Using Novel Interconnected Porous Calcium Hydroxyapatite Ceramic Hybridized with Cultured Marrow Stromal Stem Cells Derived from Green Rat. Journal of Biomedical Materials Research Part A, 69, 454-461. http://dx.doi.org/10.1002/jbm.a.30014

[4] Morita, K., Doi, K., Kubo, T., Takeshita, R., Kato, S., Shiba, T. and Akagawa, Y. (2010) Enhanced Initial Bone Regeneration with Inorganic Polyphosphate-Adsorbed Hydroxyapatite. Acta Biomaterialia, 6, 2808-2815. http://dx.doi.org/10.1016/j.actbio.2009.12.055

[5] Dorozhkin, S.V. (1997) Surface Reactions of Apatite Dissolution. Journal of Colloid and Interface Science, 191, 489497. http://dx.doi.org/10.1006/jcis.1997.4942

[6] Dorozhkin, S.V. (1999) Inorganic Chemistry of the Dissolution Phenomenon: The Dissolution Mechanism of Calcium Apatites at the Atomic (Ionic) Level. Comments on Inorganic Chemistry, 20, 285-299. http://dx.doi.org/10.1080/02603599908021447

[7] Bertazzo, S., Zambuzzi, W.F., Campos, D.D.P., Ogeda, T.L., Ferreira, C.V. and Bertran, C.A. (2010) Hydroxyapatite Surface Solubility and Effect on Cell Adhesion. Colloids and Surfaces B: Biointerfaces, 78, 177-184. http://dx.doi.org/10.1016/j.colsurfb.2010.02.027

[8] Olton, D., Li, J., Wilson, M.E., Rogers, T., Close, J., Huang, L., Kumta, P.N. and Sfeir, C. (2007) Nanostructured Calcium Phosphates (NanoCaPs) for Non-Viral Gene Delivery: Influence of the Synthesis Parameters on Transfection Efficiency. Biomaterials, 28, 1267-1279. http://dx.doi.org/10.1016/j.biomaterials.2006.10.026

[9] Meng, S., Zhang, Z. and Rouabhia, M. (2011) Accelerated Osteoblast Mineralization on a Conductive Substrate by Multiple Electrical Stimulation. Journal of Bone and Mineral Metabolism, 29, 535-544. http://dx.doi.org/10.1007/s00774-010-0257-1

[10] Abe, Y., Okazaki, Y., Hiasa, K., Yasuda, K., Nogami, K., Mizumachi, W. and Hirata, I. (2013) Bioactive Surface Modification of Hydroxyapatite. Biomed Research International, 2013, Article ID: 626452. http://dx.doi.org/10.1155/2013/626452

[11] Suda, T., Takahashi, N. and Martin, T.J. (1992) Modulation of Osteoclast Differentiation. Endocrine Reviews, 13, 6680.

[12] Väänänen, H.K., Zhao, H., Mulari, M. and Halleen, J.M. (2000) The Cell Biology of Osteoclast Function. Journal of Cell Science, 113, 377-381.

[13] Lacey, D.L., Timms, E., Tan, H.L., Kelley, M.J., Dunstan, C.R., Burgess, T., Elliott, R., Colombero, A., Elliott, G., Scully, S., Hsu, H., Sullivan, J., Hawkins, N., Davy, E., Capparelli, C., Eli, A., Qian, Y.X., Kaufman, S., Sarosi, I., Shalhoub, V., Senaldi, G., Guo, J., Delaney, J. and Boyle, W.J. (1998) Osteoprotegerin Ligand Is a Cytokine That Regulates Osteoclast Differentiation and Activation. Cell, 93, 165-176. http://dx.doi.org/10.1016/S0092-8674(00)81569-X

[14] Seeman, E. and Delmas, P.D. (2006) Bone Quality—The Material and Structural Basis of Bone Strength and Fragility. The New England Journal of Medicine, 354, 2250-2261. http://dx.doi.org/10.1056/NEJMra053077

[15] Wepener, I., Richter, W., van Papendorp, D. and Joubert, A.M. (2012) In Vitro Osteoclast-Like and Osteoblast Cells' Response to Electrospun Calcium Phosphate Biphasic Candidate Scaffolds for Bone Tissue Engineering. Journal of Materials Science: Materials in Medicine, 23, 3029-3040. http://dx.doi.org/10.1007/s10856-012-4751-y 
Scientific Research Publishing (SCIRP) is one of the largest Open Access journal publishers. It is currently publishing more than 200 open access, online, peer-reviewed journals covering a wide range of academic disciplines. SCIRP serves the worldwide academic communities and contributes to the progress and application of science with its publication.

Other selected journals from SCIRP are listed as below. Submit your manuscript to us via either submit@scirp.org or Online Submission Portal.
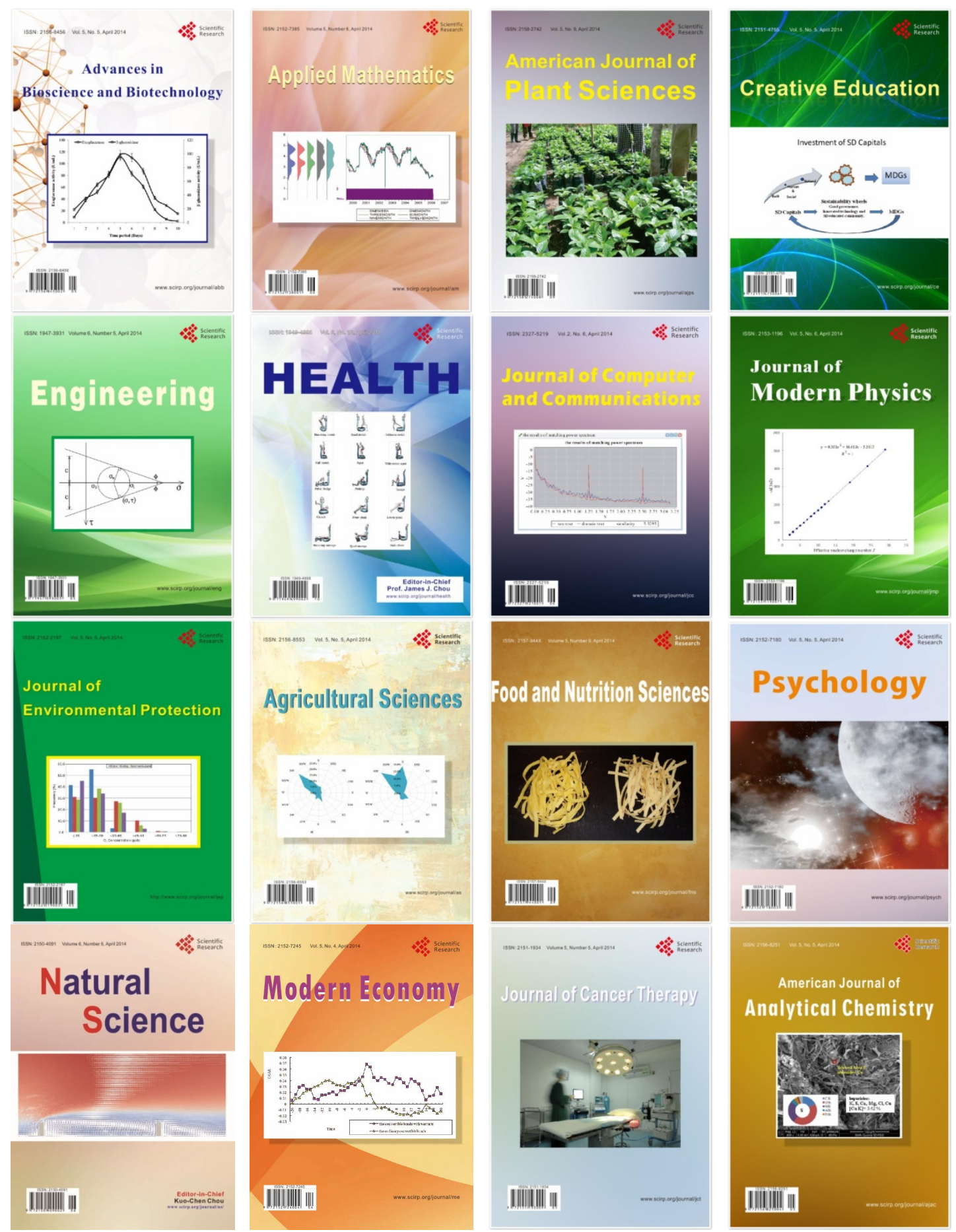